\title{
We are Honored and Delighted
}

We are honored and delighted that our journal has won a prestigious "Prose" award for being 2008's Best New Journal in the Social Sciences and Humanities, an award given by the Association of American Publisher's Professional and Scholarly Publishing Division. Humility is in order and we will try to find time for it in a later issue of the journal. We are fortunate to have an involved and talented editorial board and submissions from top writers and scholars. All of us are committed to the subject of movies and mind because it opens so many doors for our understanding of art and science, the mind and brain, ourselves and others.

The essays we publish and the books we review cover a wide spectrum of approaches to film and the mind. We try to be as ecumenical as possible for the simple reason that the complex and fascinating topics of our journal support and even require multiple approaches. The word that best describes our journal is "parallactic," an astronomical term that means the change in position of an object when seen from different places. We are fond of the term because it also has its own special use in film when describing the displacement of an object first seen though a viewfinder and then shot through the lens.

The concept of parallax makes the significant point that no single view can give us a sense of the totality of an object but that a series of perspectives can at least take us in that direction. Parallactic narrations have been a mainstay in fiction starting with Tobias Smollett's Humphry Clinker published in 1771, in which a number of characters provide their own perspectives of the same places, characters, and actions. The readers may not receive some final gestalt, some final angle of conversion of what the characters see but they do glean information from these various perspectives and certainly their interplay achieves a much fuller view of the fictional world. The sophistication and sheer drama of this approach burst on the world in 1950 with Akira Kurosawa's extraordinary film Rashomon. The film's narratives dramatize the variety of perceptions we use to understand the world around us and, in our case, to understand film and the mind.

This issue of Projections consists of four articles and a symposium on a book, all of which take different vantage points. The first article by Frank Tomasulo and Jason Grant McKahan, on Antonioni's great trilogy, does not es- 
pouse any theoretical school and at first seems to be a straightforward critical reading of the text and images. But in reality it presents an interpretation of characters and places these characters in a much wider social psychology by connecting the films to the intellectual history of the time.

The second article by Daniel T. Levin and Caryn Wang uses psychological research and the authors' experiments to demonstrate how perception of space in the real world can expand our understanding of space in film. This article is a fine example of the way in which science and the arts come together for an expanded understanding of each, an accomplishment we seek to foster in this journal. Cognitive science is now enriching and developing cognitive film studies in new and profound ways.

The third article by Esther Rashkin demonstrates how psychoanalytic theory can enrich our understanding of film, especially when the theory derives from clinical practice and especially when it is combined with such subjects as culture and history. The author revives a wonderful classic, René Clément's 1952 French film, Forbidden Games (Jeux interdits), one of the best motionpicture dramas about child psychology and mourning. Rashkin's use of psychoanalytic theory at the beginning of the article brings the readers into the depths of the little girl but soon turns outward to present an inclusive view of the Vichy government and the anti-Semitism that lies hidden beneath the film's actions.

The final article by Henry Bacon brings to film studies the very interesting concept of "conceptual blending," developed by Giles Fauconnier and Mark Turner in their cognitive study of the mind, and the Russian formalists' notion of "motivation." Bacon brings these concepts together to present a cognitive theory of the mind that applies to our perceptions of real people, art, and fantasy. Most important, he argues that our notions of people in each of these categories are constantly interacting and influencing one another.

Finally, we introduce a new feature in this issue. Instead of presenting our usual series of reviews of important new books, we focus on a single bookTom Wartenberg's Thinking on Screen-featuring two discussions of the text followed by the author's response to the reviewers. (These discussions were originally presented as a symposium at the 2007 American Philosophical Association Central Division Meeting in Chicago.) We believe the topic of the book very important and very timely. Cynthia Freeland's and Richard Eldridge's discussions as well as Wartenberg's response will familiarize the readers with the new and fast growing interdisciplinary field_Film and Philosophy. 